\title{
Formação docente: exercício da coexistência de práticas que valorizem as diferenças culturais
}

\author{
Solange Martins Oliveira Magalhães*
}

\begin{abstract}
Resumo
A sala de aula é lugar de sentidos e significados que atravessam tudo aquilo que é social. É espaço onde se estabelece o diálogo com as coisas do mundo, com a dinâmica dos grupos, e com diversos fundamentos teóricos ligados a diferentes projetos, que vão desde a transformação dos sujeitos, por meio da educação, à transformação do mundo, através dos sujeitos educados. A partir de uma concepção de educação que reclama por um processo de "democratização da cultura", buscou-se valorizar os roteiros culturais dos alunos do curso de formação de professores - Pedagogia da Terra/UFG. O foco central foi estimular, nos cursos de formação docente, a participação de alunos e professores no exercício da tolerância e coexistência de práticas que valorizem as diferenças culturais. A valorização da relação cultura-educação fez parte do processo, ajudou no exercício da coletividade, via emancipação e afirmação de direitos sociais, no entendimento e apropriação das demandas culturais dos estudantes ligados à Via Campesina.
\end{abstract}

Palavras-chave: Relação Cultura-educação; Diferenças Culturais; Diversidade cultural.

\section{Teacher training: exercise of practices coexistence that value cultural differences}

\begin{abstract}
The classroom is a place of senses and meanings that cross everything that is social. It is space in which it is established a dialogue with the things of the world, with group dynamics, and several theoretical foundations linked to different projects ranging from transformation of the subjects through education, the transformation of the world through the educated subjects. From a conception of education that calls for a process of "democratization of culture", it was aimed to enhance the cultural scripts of students, teachers training courseEarth Pedagogy/UFG. The central focus was to stimulate in teacher training courses attended by students and teachers the exercise of tolerance and coexistence practices that value cultural differences. The appreciation of culture-education relationship was part of the process, and helped in the exercise of the community, via empowerment and affirmation of social rights, in understanding and appropriation of cultural demands of the students related to country culture.

Keywords: Relation culture-education; Cultural differences; Cultural diversity.
\end{abstract}

\section{Introdução}

A cultura é todo processo humano que se constrói na prática social; a ela é delegado o mérito da interpretação do mundo, da vida, dos sujeitos, do quotidiano mas, também, dos domínios da transformação da produção do conhecimento. Fundamentalmente, a cultura ajuda a projetar o modo de ser e estar no mundo, o percurso coletivo, os acordos sociais, a partir dos quais a sociedade procura tornar-se coesa. No caso dos sujeitos, à cultura é conferido papel principal na consolidação do sujeito civilizado, autônomo, consciente; faz parte de construção de individualidades por articular dialeticamente várias dimensões sociais, que fazem parte do processo histórico da passagem dos sujeitos à sua condição de sujeitos sociais.

Por sua importância na formação dos sujeitos sociais, atualmente há crescente interesse pela cultura, inclusive pelo campo da pesquisa acadêmica, pois a ela associam-se discursos instituidores de práticas sociais que perpassam, inclusive, a educação (VEIGA-NETO, 2003).
Institui-se, assim, a relação cultura-educação e isso remete à sala de aula.

No sentido freireano, a sala de aula reclama um processo de "democratização da cultura" (FREIRE, 1983, p. 102), é lugar de sentidos e significados que atravessam tudo aquilo que é social; é o espaço onde se estabelece o diálogo com as coisas do mundo, com a dinâmica de grupos, e com diversos fundamentos teóricos ligados a diferentes projetos. Para Brandão (2014, p.66), as salas de aula são espaços de práticas pedagógicas que vão desde transformação dos sujeitos através da educação, à transformação de mundo através dos sujeitos educados.

Nesse sentido, as experiências que são inauguradas na sala de aula personificam a relação cultura-educação, como um campo de ação social transformadora. Entretanto, apesar dessa importância, em sala de aula ainda há o entendimento reduzido, deformado e até estereotipado sobre essa relação. Geralmente, a cultura é relacionada apenas às manifestações artísticas, muito embora façam parte da cultura,

* Universidade Federal de Goiás. Endereço eletrônico: solufg@ hotmail.com 
mas, raramente, relatam-se os roteiros simbólicos que a cultura concebe e articula; muito menos traduzem o entendimento de que a cultura compõe o processo da definição de concepções de mundo, valores, representações sobre si, identidades, conhecimentos, o que dificulta o reconhecimento das vozes culturais que representam os grupos sociais.

A educação deve valorizar as possibilidades de coletividade, emancipação e afirmação de direitos sociais. Conforme Chauí (2006), garantir os direitos culturais a todos os cidadãos é estimular a geração de uma nova consciência política, e isso envolve a apropriação da cultura como direito à fruição, à experimentação, à informação, à memória e à participação.

Trazendo essas observações para o campo da formação docente, a educação precisa ser compreendida como prática libertadora, a sala de aula necessita oportunizar e valorizar os roteiros simbólicos dos alunos, estimulando a participação de todos no exercício da coexistência de práticas, que aceitem e valorizem as demandas e diferenças culturais. Para Gadotti (2004), isso exige uma formação contextualizada, política, cujo processo seja calcado na realidade social dos educandos e em princípios que facilitem os processos de construção conjunta do saber, e atenção às relevâncias das inter-relações e interdependências que dão suporte às atividades dos sujeitos. No campo da formação docente, isso exige o livre exercício da práxis pedagógica, ação que pode resgatar a cidadania cultural dos sujeitos.

Assim entendendo, no movimento de respeito às diferenças culturais, nesse artigo, relatase uma experiência formativa, sob o foco da valorização da cidadania cultural dos sujeitos. Para tanto, construiu-se o seguinte trajeto: 1)historicidade do conceito moderno de cultura; 2) a cultura compreendida a partir do foco interdisciplinar; 3 ) a questão da cultura no contexto da sociedade capitalista e, 4) relato de uma atividade pedagógica que valoriza as diferenças culturais de um grupo representante da cultura campesina.

\section{A cultura: a historicidade da construção de um conceito multifacetado}

A historicidade da construção do conceito de cultura tem, na literatura do Século XV, o marco do seu primeiro significado, referindo-se ao cultivo da terra, de plantações e de animais. Etimologicamente, o termo vem do latim colere, que também significa agricultura, cultivo. $\mathrm{O}$ segundo significado emerge por volta do início do Século $\mathrm{XVI}^{2}$, quando o conceito é estendido à mente humana, passando-se a falar em mente humana cultivada. Entretanto, essa mente não era para todos, somente alguns indivíduos, grupos ou classes sociais, poderiam apresentar mentes e maneiras cultivadas ou elevado padrão de cultura e civilização, o que evidenciou um sentido classista ao conceito de cultura, que se fortaleceu nos séculos seguintes. No Século XVIII, quando do Iluminismo europeu, consolidou-se, gradativamente, o terceiro significado de cultura, classista e vinculado à civilização, evidenciando que somente as classes privilegiadas da sociedade europeia atingiriam o nível de refinamento que as caracterizaria como cultas e civilizadas.

O conceito iluminista de cultura também passou a referir-se ao aprimoramento racional e moral, tendo a civilização europeia capitalista como modelo para definir padrões de superioridade e inferioridade social, cultural, econômica e política. $\mathrm{O}$ conceito iluminista de cultura foi pautado numa epistemologia monocultural elitista, que além de responder às solicitações das elites, reforçava as relações de dominação e subordinação, a divisão social das classes e a reprodução de um ideário que cindia a sociedade em indivíduos cultos e incultos ou civilizados e não civilizados.

A cultura passa a ser pensada como única e universal, cujo acesso se dava via artes, ao bem apreciar música, literatura, cinema, teatro, pintura, escultura, filosofia. Entendia-se como cultura um conjunto de tudo aquilo que a humanidade havia produzido de melhor, fosse a termos materiais, artísticos, filosóficos, científicos, literários, e outros, que o sujeito culto deveria conhecer. A epistemologia monocultural e elitista gerou os "homens do pensamento", das letras, das artes e das ciências, e esses ganharam, em consequência, uma autoridade que superava o domínio próprio da atividade, com que cada um tinha alcançado reputação, pois as circunstâncias converteram-nos, genericamente, em figuras importantes da vida coletiva. Eles se tornaram representantes do saber, participavam do tecer do destino comum, promoviamos avanços civilizacionais ao divulgarem novas doutrinas - social, política, pedagógica, entre outras.

$\mathrm{O}$ que se percebe é que a cultura foi, gradativamente, sendo entendida em termos de maneiras de estar no mundo, produzir e apreciar obras de arte e literatura, pensar e organizar sistemas religiosos e filosóficos, produzir conhecimento, algo propício à educação. Nesse sentido, o ser sujeito culto passou a traduzir um status elevado a ser tomado como modelo, a ser atingido, o que fortaleceu a ideia de que a educação seria o caminho natural para a "elevação cultural" 
de um povo (VEIGA-NETO, 2002).

Essa ideia também associa a crença em um processo harmônico de desenvolvimento da humanidade, constituído por etapas claramente definidas, pelas quais todas as sociedades, inevitavelmente, deveriam passar (ELIOT, 1968). Muito raramente se questionou esse entendimento de cultura e, ainda hoje, se encontra vestígios desse entendimento, sobre tudo no campo da educação. Portanto, para se atingir um suposto grau mais elevado de desenvolvimento, passou-se a buscar a equivalência de uma educação que seguisse os rumos das sociedades europeias. Em termos culturais, passou-se a buscar formar uma identidade única, ao mesmo tempo em que havia a rejeição de toda e qualquer diferença (VEIGA-NETO, 2002).

Somente no Século XX, a monocultura elitista foi colocada em questão pela filosofia, antropologia, linguística e parte da sociologia, buscava-se o reconhecimento da impossibilidade da homogeneização cultural, firmava-se o entendimento que a cultura não era apenas um conjunto de produtos acabados e finalizados, que podem ou devem ser transmitidos ou recebidos pelos outros sujeitos. Referendava-se a cultura como relação social, prática de significação, política, produtora de identidades e diferenças.

Gradativamente, aceitava-se a ideia da existência de várias "culturas", todas legítimas e, como afirmou Silva (2003, p. 17), apesar de alguns grupos sociais estarem em posição de impor seus significados sobre outros, a cultura passou a ser compreendida como processo, que ocorre num "contexto de relações sociais de negociação, de conflito e poder". Apesar de isso ser esperado numa sociedade cindida em classes, quem teve e continua tendo mais condições de impor os seus significados como válidos, manifesta esse poder de imposição, o que não quer dizer que haja passividade, o processo sempre implica resistência, possibilidade de subversão, transgressão, como afirmam Apple e Buras (2008).

Na sequência histórica, ao longo do Século $\mathrm{XX}$, os domínios do que se costumava designar como cultura, se expandiu e diversificou, tornou-se o grande elemento revitalizador do pensamento nas Ciências Humanas, superando-se o conceito monolítico de acumulação de saberes, via processo estético, intelectual ou espiritual.

No Século XXI, ressaltou-se a dimensão simbólica da cultura, ou seja, o que faz em vez de acentuar o que ela é. Essa mudança ajudou a fortalecer um conceito de cultura como prática social, com características históricas, implicações teóricas e compromissos éticos e políticos.

Analisando essa trajetória histórica, associamo-nos a Costa; Silveira e Sommer (2003, p. 36. Grifos nossos), para resumir a construção do significado moderno de cultura:

[...] Cultura transmuta-se de um conceito impregnado de distinção, hierarquia $e$ elitismos segregacionistas para um outro eixo de significados em que se abre um amplo leque de sentidos cambiantes $e$ versáteis. Cultura deixa, gradativamente, de ser domínio exclusivo da erudição, da tradição literária e artística, de padrões estéticos elitizados e passa a contemplar, também, o gosto das multidões. Em sua flexão plural - culturas - e adjetivado, o conceito incorpora novas e diferentes possibilidades de sentido. É assim que podemos nos referir, por exemplo, à cultura de massa, típico produto da indústria cultural ou da sociedade techno contemporânea, bem como às culturas juvenis, à cultura surda, à cultura empresarial, as culturas infantis, ou às culturas indígenas, expressando a diversificação e a singularização que o conceito comporta.

\section{O conceito de cultura numa perspectiva interdisciplinar}

À historicidade do conceito moderno de cultura somam-se as necessidades impostas numa sociedade liberal e democrática, essas dizem da exigência moral de se colocar a cultura ao alcance de todos os sujeitos, quer seja por meio da educação ou via promoção e subvenção das artes, das letras e das demais manifestações culturais (LLOSA, 2013). Essa ideia foi construída com a colaboração de vários autores que transitam no campo da Antropologia, Psicologia e Sociologia, dentre outros, a saber: Tylor (1871), Keesing (1974), Bakhtin (2006), Laraia (1997), Brandão (2002), Mello (1986), Hall (1997), Arendt (1991), Lakatos (1979), Horton e Hunt (1980), Geertz (1989; 2008), e Llosa (2013). No conjunto, esses autores representam a construção do percurso interdisciplinar do conceito de cultura.

Tylor (1871) foi o primeiro autor a formular o conceito de cultura do ponto de vista antropológico. Para ele, a cultura é o todo complexo que inclui conhecimentos, crenças, arte, moral, leis, costumes ou qualquer outra capacidade ou hábitos adquiridos pelo homem enquanto membro de uma sociedade. Ele enfatizou a importância do aprendizado da cultura, em oposição à ideia de aquisição inata, no desenvolvimento dos sujeitos 
culturais.

No trabalho de Keesing (1974) se tem a argumentação teórica sobre a forma como o conceito de cultura era analisado, o autor definiu três tipos de teorias: 1) sistema cognitivo ou de conhecimento, indicando que a cultura pode ser compreendida a partir de tudo aquilo que os sujeitos precisam conhecer ou acreditar, para conviver dentro da sociedade; 2) sistemas estruturais que definem a cultura como um sistema simbólico, um sistema de símbolos e significados, partilhados pelos sujeitos que compreendem as regras sobre relações e modos de comportamento; 3) sistema adaptativo ou responsável por padrões de comportamento, socialmente transmitidos, que servem para adaptar as comunidades humanas, ao seu modo de vida socialmente estipulado (tecnologias, modo de organização econômica, padrões de agrupamento social, organização política, crenças, práticas religiosas, etc.). Tylor (1871) e Kessing (1974) coligam suas ideias no entendimento que a cultura é uma lente, por meio da qual o sujeito aprende, significa e adapta-se ao mundo.

Geertz (2008, p. 14) amplia a ideia ao referir-se acultura como essencialmente semiótica. Para o autor, cultura é:

[...] modo de vida global de um povo; [...] legado social que o indivíduo adquire do seu grupo; [...] uma forma de pensar, sentir $e$ acreditar; [...] uma abstração do comportamento; [...] uma teoria, elaborada pelo antropólogo, sobre a forma pela qual o grupo de pessoa se comporta realmente; [...] um celeiro de aprendizagem em comum; [...] um conjunto de orientações padronizadas para os problemas recorrentes; [...] comportamento aprendido; [...] um mecanismo para regulamentação normativa do comportamento; [...] um conjunto de técnicas para se ajustar tanto ao ambiente externo como em relação aos outros homens; [...] um precipitado da história.

Para o autor, assumir que a cultura é semiótica, significa afirmar que ela carrega símbolos e que esses podem ser traçados de uma forma inteligível e com densidade. E ainda, que são regidos por ordens discursivas, descritas de forma inteligível num meio social. No mesmo percurso, Costa (2000, p. 32) explica que as "sociedades e culturas em que vivemos, são dirigidas por poderosas ordens discursivas, essas regem o que deve ser dito e o que deve ser calado", os próprios sujeitos não podem ficar isentos desses efeitos. É desse modo que se criam relações discursivas de saber-poder, o que faz da cultura, um grande espaço de discussões.

Hall (1997, p. 20) complementa a ideia de Costa ao afirmar que:

[...] a cultura é um dos elementos mais dinâmicos - e mais imprevisíveis - da mudança histórica do novo milênio. Não devemos nos surpreender, então, que as lutas pelo poder deixem de ter uma forma simplesmente física e compulsiva para serem cada vez mais simbólicas e discursivas, e que o poder em si assuma, progressivamente, a forma de uma política cultural.

Com os autores, pode-se concluir que a cultura é um local de diferenças e de lutas sociais (JOHNSON, 1999), que cada sociedade constitui sua própria cultura, por meio da linguagem, dos discursos, das relações de poder, das imagens e das produções, inclusive do conhecimento, que em conjunto, determinam roteiros simbólicos produzindo a identidade cultural de um povo.

Conforme o pensamento de Bakhtin (2006), o roteiro simbólico diz sobre a lógica da comunicação ideológica e sua influência na formação das consciências. Fundamentado no pensamento marxista, o autor resgata que as relações de produção e a estrutura sociopolítica que delas derivam, determinam formas e os meios de comunicação verbal possível entre indivíduos. Na nossa sociedade, sob uma perspectiva de luta de classes, tem-se que a classe dominante constrói e reforça um sentido ideológico, com o objetivo de ocultar as contradições presentes nas relações de classes e ao fazer isso, torna a linguagem (e a cultura) um signo monovalente.

Como a cultura é semiótica (GEERTZ, 2008), a palavra ou o signo monovalente que é sempre carregado de conteúdo ideológico unilateral, inviabiliza a compreensão da história da constituição das ideologias, das lutas de classe, das crenças e das materialidades que atravessam a nossa existência. Isso influi na gênese da cultura, a qual vai surgir apenas para responder as necessidades da classe dominante. Com a linguagem monovalente, a cultura torna-se um processo alienante (HORTON; HUNT, 1980).

Dialeticamente, os sujeitos são capazes de reagir (ARENDT, 1991), nunca são simples agentes de cultura, ao mesmo tempo, são produtos e produtores do mesmo processo (LAKATOS, 1979).

Pode-se concluir que a partir de uma ótica 
interdisciplinar, a cultura é roteiro simbólico, que configura um movimento promotor de individualização dos sujeitos, que sempre são perpassados por contradições. Conforme afirma Brandão (2002, p. 16-17), a cultura "existe tanto fora de nós, em qualquer dia de nosso cotidiano, quanto dentro de nós (...) somos seres obrigados a aprender, desde crianças e pela vida afora, a compreender as suas várias gramáticas e a falar as suas várias linguagens".

\section{A cultura no contexto da sociedade capitalista: a base de uma experiência com a cultura campesina}

Como foi exposto, sem a cultura o conjunto social não progride e nem se mantém coeso. Contudo, no atual contexto da globalização e da mundialização do capitalismo e dos mercados, ocorrem mudanças importantes no âmbito da cultura, capazes de torná-la cindida e destituída de valores humanistas. Em outras palavras, na sociedade do consumo imediato, os valores que se destacam são fixados pelo mercado, enaltecidos pela cultura global, que aproxima e busca igualar as diferentes tradições, línguas, crenças, instituindo, em última instância, uma cultura de massas. Essa cultura de massas empobrece a força motriz da vida cultural, isso implicando empobrecimento do humano.

No processo, o sujeito se torna fútil, privado de lucidez e livre-arbítrio, com individualismo extremo, e o faz "reagir à cultura dominante de maneira condicionada e gregária" (LLOSA, 2013, p. 22-25). Ideologicamente, a cultura é desnaturalizada e depreciada, equiparada para tudo uniformizar.

Como a cultura continua sendo necessária à humanização, cada classe social segue produzindo-a como the convém, mesmo compartilhando com outras classes sociais, muitas coisas em comum como a língua mater e a religião. Paradoxalmente, apesar de se evidenciarem diferenças marcantes relacionadas à condição econômica, horizontes de experimentação, valores éticos e estéticos, os vários roteiros culturais seguem coexistindo, o que leva diretamente a um velho problema: a relação culturaeducação.

Hoje se recoloca de forma enfática o tema da relação entre a cultura e a educação, tenta-se ressignificá-la para entender os vários roteiros culturais, que invadem as salas de aula. Entende-se que pode ajudar a melhorar o convívio pedagógico que envolve situações convergentes e divergentes. Afinal, a sala de aula é um espaço de constantes manifestações de diferenças culturais, essas educam, integram, ampliam e, às vezes, podem desalienar e libertar no exercício da coexistência de práticas educativas emancipadoras.

Esse entendimento passa a ser aqui representado pelo relato de uma experiência pedagógica, vivida na disciplina Sociedade, Cultura e Infância, com 59 alunos, do curso de Pedagogia da Terra $^{3}$, Turma Salete Strozake, da Faculdade de Educação, Universidade Federal de Goiás (FE/UFG). Esse curso foi fruto de um convênio entre Instituto Nacional de Colonização e Reforma Agrária (Incra), Programa Nacional de Educação nas Áreas de Reforma Agrária (Pronera) e a Via Campesina, liga internacional de camponeses,representada pelos movimentos sociais do campo e pastorais, a saber: Movimento dos Trabalhadores Rurais Sem Terra (MST), Movimento dos Atingidos por Barragens (MAB) e, ainda, pelo Movimento Camponês Popular (MCP), que, naquele momento, não fazia parte da Via Campesina, Pastoral de Juventude Rural (PJR) e Comissão Pastoral da Terra (CPT), conforme Sobrinha (2012).

A escolha do grupo teve como base a singularidade dos sujeitos e as diferentes práticas culturais, manifestadas pelos alunos, representantes da educação do campo. Todos eram advindos de várias regiões do país. Como professora formadora do curso, não houve como deixar de observar a presença dos vários saberes, esses eram sucedidos do mundo concreto e real dos alunos. Saberes que precisavam ser somados e impulsionados na formação acadêmica em desenvolvimento.

Esses aspectos suscitaram o objetivo de buscar compreender a relação cultura-educação no processo ensino-aprendizagem, uma busca reforçada por Cunha $(1998$, p.41), quando afirma que o professor constrói sua ação pedagógica a partir inúmeras referências, "entre elas estão sua história familiar, sua trajetória escolar e acadêmica, sua convivência com o ambiente de trabalho, sua inserção cultural no tempo e no espaço". Com Cunha, entende-se que o processo organização de narrativas na sala de aula se dá a partir das referências culturais. Esse entendimento faz com que professor e alunos descubram os significados que têm atribuído aos fatos que vivem e, assim, no movimento pedagógico, podem até reconstruir a compreensão que têm das coisas e de si mesmos.

A partir desse foco, passa-se a pensar a formação docente como práxis; promotora de educação para além do capital (MÉSZÁROS, 2007); processo que ressalta a complexidade dos sujeitos, apesar das inúmeras contradições, das diversas experiências que se manifestam nos processos formativos, como é o caso da Pedagogia da Terra. 
No que se refere à relação cultura-educação, promovida no curso, exigiu a interlocução da cultura campesina com a acadêmica, num movimento de busca do entendimento e valorização da organização interna dos estudantes, denominada por eles como núcleos de base ou espaços de organicidade da turma Salete Strozake. Nesses núcleos, por exemplo, ocorriam debates, estudos, realização de atividades pedagógicas, avaliação de discussões coletivas e individuais, e outros encaminhamentos (saúde, nascimentos, casamentos, desistências, etc.) dos estudantes do curso. Os núcleos eram assim definidos:

Núcleo de Base Salete Strozake, "Estudo, trabalho, luta permanente, marco de Salete na via está presente!"; Núcleo de Base Josué de Castro, "Josué de Castro, semeador de ideias, lutou com coragem contra a fome e a miséria!"; Núcleo de Base Sepé Tiarajú, "Índio brasileiro, na luta por justiça somos companheiros!"; Núcleo de Base Paulo Freire, "Dos campos as sementes, dos povos a paixão, Paulo Freire é exemplo, educador dessa nação!"; Núcleo de Base Rosa Luxemburgo, "Somos a semente que Rosa semeou, lutamos pelo mundo com o qual ela sonhou!"; Núcleo de Base Keno, "Keno Guerreiro lutou com o coração, lutou com a consciência, contra a transgenização!" e Núcleo de Base Cora Coralina, "Cora Coralina vive em cada um de nós, a Via Campesina eleva sua voz!" (SOBRINHA, 2012, p. 67-68).

Nos cursos regulares de Pedagogia, não há a constituição de núcleos de base, e muito menos a discussão da organização dos alunos e do curso, seus valores, lideranças, tomadas de decisões. Isso tornou os núcleos muito interessantes, no sentido de entender como o grupo de alunos da Pedagogia da Terra pensava e resolvia os problemas concretos, do seu dia-a-dia, como por exemplo: conviver pacífica e organizadamente, em um espaço físico mínimo e restrito - três salas de aulas eram utilizadas como dormitório, um banheiro feminino e um masculino, mais o pátio da faculdade, onde ocorria uma série de atividades como alimentação, debates, votações, exposições, festas e cirandas.

Além da organização dos núcleos de base, ainda existiam as equipes de apoio, como: equipe de mística, equipe de animação e cultura, equipe de comunicação, equipe da ciranda infantil, equipe de infraestrutura, equipe de finanças, equipe da memória coletiva, equipe de esportes, equipe de disciplina, equipe de saúde e equipe de formatura.
Ambos com coordenação rotativa, como uma forma de garantir a todos, o aprendizado necessário à tomada de decisões na formulação de acordos, para a convivência pacífica e coletiva.

Dentre as atividades das equipes e apoio, destaca-se aqui aquela relacionada à espiritualidade na forma de execução de místicas, foco central nesse relato, pois foia atividade que mais se destacou no contexto da universidade: por serem, particularmente, diferentes das atividades acadêmicas, por revelarem um momento profundamente cultural, que marcou a memória de muitos estudantes e professores (CODINA, 1996).

As místicas eram realizadas todos os dias, antes do início das aulas, de segunda a sábado, por 30 min, no saguão principal da FE/UFG. Aconteciam conforme relato de Sobrinha (2012, p. 68):

Durante a realização das místicas, as equipes responsáveis, representadas pelos núcleos de base, uma equipe diferente a cada dia, sempre utilizavam algum elemento representativo da cultura camponesa ou dos movimentos sociais do campo e pastorais da terra, como bandeiras, elementos naturais como o fogo, a água, a terra elou as sementes dos alimentos, artesanato popular, instrumentos de trabalho usados no campo, livros, materiais escolares, cartazes, faixas, etc.

As místicas eram preparadas pela equipe de apoio, o grupo se reunia, discutia e, intuitivamente, procurava representar as demandas do grupo. As místicas deveriam traduzir as demandas do grupo, representavam a jornada formativa, ou serviam para o fortalecimento das amizades e da coletividade, liderança e trabalho, respeito, historicidade da luta camponesa, aspectos políticos do grupo, entendimento do mundo acadêmico, casamentos, nascimentos e até mortes - eles tiveram casamentos, perdas e nascimentos durante o curso, dentre outros. Reporta-se à sensibilidade de Sobrinha (2012, p. 68 ), quando a autora relata que houve intensa criatividade, durante a realização das místicas, ao longo do curso. Conforme a autora, as místicas se tornaram "(...) espaços formativos e de renovação das concepções, dos sentimentos, das emoções e da construção de sentidos que alimentavam e fortaleciam os estudantes".

Conforme o entendimento de cultura até aqui formulado, as místicas traduziam roteiros simbólicos da cultura campesina, e como tal, despertaram muitas disputas de poder na instituição. Essas disputas envolveram grupos contra as místicas 
ou a seu favor, nesse caso, por entendê-las como manifestação cultural. Em vários momentos do curso, as místicas não foram compreendidas, quer seja por parte do corpo docente, administração e/ou funcionários. Alguns relataram que elas eram percebidas, como um rito desnecessário, às vezes, até esquisito. Entende-se tal postura, pois se não se estivesse envolvido nos roteiros simbólicos do grupo, dificilmente se entenderia determinadas místicas, como, por exemplo, as cantorias altas, alegres e vibrantes, o que dificilmente acontece no rol de uma faculdade. Em outros momentos, a mística tratava a questão da morte - houve a morte de um colega durante o curso -, como parte do ciclo da vida. Em outro momento, quando uma professora do curso ficou gravemente doente, a mística realizada falava das forças transformadoras da natureza, do como ela dá vida e tudo regenera. Especialmente, no dia dessa mística, as flores, sementes e objetos utilizados, o canto e os escritos, foram levados pelo grupo para a professora adoentada, como uma forma de entregar-lhe a força resgatada pelo grupo.

Por esses aspectos e muitos outros, as místicas foram proibidas durante certo tempo, mas voltaram a acontecer após a luta do grupo, por seu grande valor simbólico para os estudantes da Pedagogia da Terra. Confirmando a afirmação de Chauí (2006, p. 138):

[...] a cultura não se reduz ao supérfluo, ao entretenimento, aos padrões do mercado, à oficialidade doutrinária (que é ideologia), mas se realiza como direito de todos os cidadãos, direito a partir do qual a divisão social das classes ou a luta de classes possa manifestar-se e ser trabalhada porque, no exercício do direito à cultura, os cidadãos, como sujeitos sociais e políticos, se diferenciam, entram em conflito, comunicam e trocam suas experiências, recusam formas de cultura, criam outras $e$ movem todo o processo cultural.

Por outro lado, a luta pela execução das místicas significava a construção de uma história de busca e reconciliação entre os sujeitos e a liberdade, essa ação, em muitos casos, não dispensou uma subversiva ação social, de teor eminentemente político, no domínio da cultura (BRANDÃO, 2014). Ao final, a luta pela realização das místicas, recebeu uma conotação de luta política, realizada sobre a cultura e através da cultura. Concorda-se com Brandão:

Assim como um momento da história pode ser o da tomada do poder por grupos opressores, que sujeitam os processos sociais de construção da cultura aos seus interesses, um outro momento pode ser o da conquista de um novo poder que recupere, não só para o povo, mas para todos os homens, as dimensões perdidas das relações humanas, humanizadas $e$ humanizadoras do trabalho e da cultura (BRANDÃO, 2014, p. 59).

O sentido e os significados que as místicas têm para os movimentos sociais do campo e pastorais da terra são assim descritos por Sobrinha (2012, p.68) por meio das falas dos estudantes:

Esperança e motivação para seguir em frente (...) (Estudante 1).

Mística não é teatro, ela é atitude, força, sentimento (...) é força crítica precisa, é a representação do mistério e o porquê da luta e das coisas extraordinárias que nos motivam a viver e lutar (Estudante 32).

A mística no nosso entendimento é toda essa espiritualidade que aproxima a nossa utopia, o nosso sonho para nossa realidade é representação de um projeto político (Estudante 13).

Conforme relatos dos estudantes, a mística fala do que o povo não explica, só sente. É mistério que cada um pode sentir de modo diferente (Estudante 31).

As dificuldades enfrentadas evidenciaram uma lógica de embrutecimento, por parte da instituição e alguns de seus membros, quando a mesma precisaria considerar todas as diferenças culturais, ao longo do processo formativo. Negar, proibir a expressão das diferenças culturais, seria o mesmo que negar a capacidade de resolução, criação, dos sujeitos e dos grupos. Conforme Rancière (2007), a formação que busca a emancipação intelectual dos sujeitos precisa romper com uma ordem explicadora do mundo e das coisas, ao mesmo tempo em que exige considerar a vontade de aprender dos sujeitos, em parceria com trabalho educativo emancipador de consciências (FREIRE, 1997; SOBRINHA, 2012).

A negação das místicas acabou deflagrando uma questão importante: a formação ainda procura impor e controlar o conjunto de práticas significantes dos grupos. Afortunadamente, na sala de aula realizou-se a problematização do assunto - 
as místicas e sua negação, tornando-a um espaço ecológico de cruzamento de culturas e saberes (PÉREZ GÓMEZ, 1998).

Como mostra o percurso teórico empreendido, os princípios que originam e que qualificam a cultura campesina, presente no curso da Pedagogia da Terra, representava os roteiros simbólicos construídos pelo grupo, envolvidos pelo seu sentido de libertação sociocultural. Como em sala não se negou sua relevância vital, social e política, da prática cultural do grupo, houve a superação da sujeição imposta aos sujeitos, o que os ajudou na luta contra o modelo imposto pelo ensino superior hegemônico.

Nesse sentido, a sala de aula tornou-se um ethos cultural, lugar de viver a liberdade, o que, segundo Freire (1997), implica na conscientização dos sujeitos de seus condicionamentos sociais. Isso abre caminho a sua intervenção no mundo, pois sustenta uma base gnosiológica, ou seja, seus valores éticos e políticos. Nas discussões empreendidas, os alunos se assumiam como sujeitos de direitos, cidadãos com direito de expressão.

A experiência do debate sobre as místicas, que ocorreram ao longo de um semestre, mostrou que a valorização da cultura campesina, promoveu análises e interações das influências plurais, que acultura exerce sobre $o$ processo ensinoaprendizagem. Foi possível perceber que o sentido e a consistência do que os alunos aprendiam na vida acadêmica, poderia ser qualificava no cruzamento sempre vivo, fluido e complexo de suas experiências culturais. E ainda, na dinâmica da sala de aula, houve a discussão de valores hegemônicos e contra hegemônicos, debateu-se sobre as pressões do cotidiano da cultura institucional, presente nos papéis, nas normas, nas rotinas e nos ritos próprios da instituição educativa. Essas rotinas também tiveram que ser trabalhadas, às vezes com muita resistência, por parte de alguns alunos (exigência de trabalhos, notas, frequência, horários, etc.); sua aceitação e entendimento, também se deu no mesmo influxo de aceitação das diferenças culturais.

Gradativamente, a dinâmica rompeu com a tendência homogeneizadora e padronizadora, que impregna as práticas educativas, ajudando a superar as dificuldades apontadas por Moreira e Candau (2003, p. 161): os professores em suas salas de aula mostram "dificuldade em lidar com a pluralidade e a diferença", por isso, tentam "silenciá-las e neutralizá-las". No contra fluxo, a experiência mostrou que valorizar a relação cultura-educação acolhe,favorece a crítica, coloca em contato saberes, manifestações e entendimentos, a partir de óticas diferentes. No processo, as culturas conversam, trocam experiências, se misturam e ressoam, em um contínuo humano, por ser sempre ressonância.

\section{Algumas considerações: Aprendendo com o exercício da tolerância às diversidades culturais $\mathrm{e}$ a valorização da cultura}

A cultura não é um elemento exterior à sociedade, de modo a completá-la. Tampouco, se deve reduzi-la às manifestações artísticas, embora seja esta uma de suas dimensões; ou apenas a representação dos costumes de determinado período histórico ou sociedade. A cultura representa todas as manifestações dos homens, relativas à práxis social. Por isso, sua desvalorização, sobretudo nos processos formativos, tem efeito avassalador sobre a formação dos sujeitos.

Como afirmou Freire (1980, p.109):

[...] o homem faz ao mundo que não fez. A cultura é o resultado de seu trabalho. Do seu esforço criador e recriador. [...] Descobriria que tanto é cultura o boneco de barro feito pelos artistas, seus irmãos do povo, como cultura também é a obra de um grande escultor, de um grande pintor, de um grande músico, ou de um pensador. Que cultura é a poesia dos poetas letrados de seu país, como também a poesia de seu cancioneiro popular. Que cultura é toda criação humana.

Junto de Freire, assume-se sua afirmação sobre o fato de que somos sujeitos socioculturais, participantes da estrutura social, construtores de roteiros simbólicos, de pluralidade cultural. Na experiência com o grupo da Pedagogia da Terra, a cultura aparece como aspecto fundamental na reflexão sobre os sujeitos, suas vidas, exercício e poder, e sobre a própria formação docente apresentada. Pensar as culturas relativizando-as e generalizando seus aspectos, é desvalorizar o ethos cultural dos sujeitos, sua visão de mundo, valores, construções e práticas que, no conjunto, compõem os sujeitos sociais (GEERTZ, 2008).

$\mathrm{Na}$ experiência apresentada, as representações culturais do grupo da Pedagogia da Terra mostraram que as estruturas de significado envolvem todos os sujeitos de uma mesma cultura. No caso particular das místicas, os estudantes mostravam-se imersos em seus valores, aglutinando aspectos objetivos e subjetivos de suas vidas. Para os alunos, o respeito a suas culturas, denotava o afastamento da postura positivista. Entender e incorporar a importância de seus roteiros simbólicos permitiu a interação e a criação dos símbolos norteadores da vida social e profissional daqueles 
estudantes.

A experiência mostrou que quando se está imerso no universo simbólico e cultural, partilha-se símbolos, conceitos, valores. A formação docente traduz essa compreensão como realidade verossímil para os alunos, quando possibilita estudar e pensar sobre as diferenças dos sujeitos, seus contextos e costumes. Nesse sentido, é especialmente incisivo que os professores sejam desafiados a incorporar, em suas práticas educativas, os roteiros culturais dos estudantes. Finaliza-se afirmando que a pluralidade cultural se apresenta de forma impetuosa e imperiosa, em todos os espaços sociais, inclusive nas salas de aula. Não saber lidar com ela, frequentemente, acarreta confrontos e conflitos, tornando cada vez mais agudos os desafios a serem enfrentados nas salas de aula. Afinal, como salienta Brandão (2002), temos "culturas", somos portadores de cultura e ela nos humaniza.

\section{Notas}

1 Pesquisa financiada pelo CNPQ - Conselho Nacional de Desenvolvimento Científico e Tecnológico e pela FAPEG - Fundação de Apoio à Pesquisa do Estado de Goiás.

2 No final do Século XVIII, surge o termo germânico Kultur que era utilizado para simbolizar todos os aspectos espirituais de uma comunidade, em contraposição com a palavra francesa Civilization referia-se principalmente às realizações materiais de um povo.

3 "O curso recebe a denominação de Pedagogia da Terra por sua forte vinculação à luta pela terra, à luta pela reforma agrária e pela relação que os camponeses possuem com a terra e com o planeta Terra, como espaço de vida, de criação e de transformação, expressão que também manifesta a sabedoria dos povos do campo (...). O curso ocorreu no período de 1997-2011, e recebe destaque sua proposta de educação para além do capital, (...) além de ser necessário cultivar a sabedoria camponesa" (SOBRINHA, 2012, p.56).

\section{Referências}

APPLE, M. W. E BURAS, K. L. Currículo, poder e lutas educacionais: com a palavra, os subalternos. Porto Alegre: Artes Médicas, 2008.

ARENDT, H. A condição humana. 5. ed. Rio de Janeiro: Forense Universitária, 1991.
BAKHTIN, M. Marxismo e filosofia da linguagem. São Paulo: Hucitec, 2006.

BRANDÃO, C. R.A Educação Como Cultura. 2. ed. São Paulo: Brasiliense, 2002.

. Paulo Freire: a educação, a cultura e a universidade. Memória de uma história de cinquenta anos atrás. Revista EJA EM DEBATE, Florianópolis, ano 3, n. 4. jul. 2014.

CHAUÍ, M. Cidadania cultural: o direito à cultura. São Paulo: Fundação Perseu Abramo, 2006.

CODINA, V. Ecologia Simbólica da Terra. São Paulo: Edições Loyola, 1996.

COSTA, M. V. Estudos culturais: para além das fronteiras disciplinares. In: COSTA, M. V. (Org.). Estudos culturais em educação. Porto Alegre: Editora da UFRGS, 2000.

COSTA, M.; SILVEIRA, R. H.; SOMMER, L. H. Estudos culturais, educação e pedagogia. Rev. Bras. Educ.[online]. 2003, n.23, pp. 36-61.

CUNHA, M. I. $O$ professor universitário na transição de paradigmas. Araraquara: JM Editora, 1998.

ELIOT, T. S. Notes Towards the Definition of Culture. London: Faber and Faber, 1968.

FREIRE, P. Conscientização e alfabetização: uma nova visão do processo. In: FAVERO, O. Cultura popular, educação popular: memória dos anos sessenta. Rio de Janeiro: Graal, 1983.

Pedagogia da autonomia. Rio de Janeiro: Paz e Terra, 1997.

GADOTTI, M. Pedagogia da terra: Ecopedagogia e educação sustentável. Disponível em: http://ww w.saber.ula.ve/mundouniversitario/archivospdfs/nu m10_julio2004/moicer_gadotti_pedagogia_terra.pdf Acesso em: 08/06/2014

GEERTZ, C. A interpretação das culturas. Rio de Janeiro, Zahar Editores, 2008.

Uma descrição densa: por uma teoria interpretativa da cultura. In: GEERTZ, C. A interpretação das culturas. Rio de Janeiro, Zahar Editores, 2008. 
HALL, S. Cultural studies and its theoretical legacies: MORLEY, David, KUANHSING, C., (eds). Hall Stuart - critical dialogues in cultural studies. London; New York: Routledg, 1996.

HORTON, P. B.; HUNT, C. L. Sociologia. São Paulo: Mc Graw Hilldo. Brasil, 1980.

JOHNSON, R. O que é, afinal, estudos culturais? In: SILVA, T. T. da, (org.). O que é, afinal, estudos culturais. Belo Horizonte: Autêntica, 1999.

KEESING, F. Antropologia cultural. Rio de Janeiro, Fundo de Cultura, 1961.

LAKATOS, I. O Falseamento e a Metodologia dos Programas de Pesquisa Científica. In: LAKATOS I.; MUSGRAVE A. (Org.). A Crítica $e$ o Desenvolvimento do Conhecimento. São Paulo: Cultrix, EDUSP, p. 109-243. 1979.

LARAIA, R. de B. Cultura um conceito antropológico. Rio de Janeiro, Zahar: 1997.

LARROSA, J.; SKLIAR, J. Habitantes de Babel: políticas e poéticas da diferença. Belo Horizonte: Autêntica. Tradução de Semíramis Gorini da Veiga, 2002.

LLOSA, M. V. A Civilização do Espetáculo: uma radiografia da cultura do nosso tempo. Rio de Janeiro: Objetiva, 2013.

MELLO, L. G. de. Antropologia Cultural.Petrópolis: Vozes, 1986.
MÉSZÁROS, I. A educação para além do capital. In: $O$ desafio e o fardo do tempo histórico: o socialismo no século XXI. Tradução: Ana Cotrim, Vera Cotrim. São Paulo: Boi Tempo, 2007.

MOREIRA, A. F. B. e CANDAU, V. M. Educação escolar e cultura(s): construindo caminhos. Revista Brasileira de Educação. N. 23, p. 156-168, 2003.

PÉREZ GÓMEZ, A. I. La cultura escolar em La sociedad neoliberal.Madrid: Morata,1998.

RANCIÈRE, J. Uma aventura intelectual. In: RANCIÈRE, J. $O$ mestre ignorante: cinco lições sobre a emancipação intelectual. Trad. Lílian do Valle. Belo Horizonte: Autêntica, 2007.

SILVA, T. T.O currículo como fetiche: a poética e a política do texto curricular. Belo Horizonte: Autêntica, 2003.

SOBRINHA, D. E. N. Vida, formação e educação: o curso de Pedagogia da Terra. Dissertação de Mestrado. Faculdade de Educação da UFG. Goiânia. 2012.

SANTOS, B. S. (2002). Para uma sociologia das ausências e das emergências. Revista Crítica de Ciências Sociais, 63, 237-280.

TYLOR, E. B. Primitive Culture, 1871. Disponível em: <http://www.infopedia.pt/\$edward-burnetttylor>. Acesso em 05/06/2014

VEIGA-NETO, A. Cultura e currículo. Contrapontos, v. 2, n 4, jan-abr., p. 43-51, 2002.

\section{Sobre a autora}

Solange Martins Oliveira Magalhães é Psicóloga, Doutora em Educação, Professora do Curso de Pedagogia e do Programa de Pós-graduação em Educação, Faculdade de Educação, Universidade Federal de Goiás.

Recebido em fevereiro de 2015.

Aprovado em novembro de 2015. 